\title{
The Dependence of Airport Profit on Passenger Satisfaction and Operational Efficiency
}

\section{Roman Vokáč ${ }^{1 *}$, Milan Lánský ${ }^{1}$, Stanislav Szabo ${ }^{1,2}$}

\author{
${ }^{1}$ Department of Air Transport, Faculty of Transportation Sciences, Czech Technical University in Prague, Prague, \\ Czech Republic \\ ${ }^{2}$ Faculty of Aeronautics, Technical University of Košice, Košice, Slovak Republic \\ *Corresponding author: Czech Technical University in Prague, Faculty of Transportation Sciences, Department of Air \\ Transport, Horská 3, 12803 Prague, Czech Republic, Email: vokacrom@fd.cvut.cz
}

\begin{abstract}
Since the airports are in fact commercial companies, their main objective is to make profit. Therefore, it is important for the airports to identify the business activities that may increase the income as well as those that may reduce the costs. The terminal process, handling the passengers' baggage both on their departure and arrival, is a basic process at all airports that are intended for the commercial air transport. The quality of the terminal process provided by the airports has a significant impact on the passengers especially in terms of their satisfaction. In this text, the passenger satisfaction is regarded as a key factor of the terminal process affecting a whole range of other areas. Its high efficiency leads to cost reduction from the perspective of the airport. As it is proposed here, there is a connection between the passenger satisfaction and the process efficiency. For example, the queues that form due to the check-in process may be a result of the imbalance between the passenger arrival rate and the service rate. Therefore, there is a necessity of improving not only the passenger satisfaction but also the process efficiency.
\end{abstract}

Keywords

Airport - Efficiency - Profit - Queue - Satisfaction

\section{Introduction}

The modern airports increase their incomes by various business activities that are not necessarily associated with the air transport operation only. Renting the advertising spaces and premises for commercial use, selling refreshment and so on may be the examples. The amount of the income from these activities is considerably depending on the passenger satisfaction. Hence, improving the passenger's experience is a common priority of all parties involved. Furthermore, if attained, the costs decrease too as far as the check-in process is concerned. 
Next, the reduction of the operation costs should be also considered. A possible goal may be an optimal operation when the maximal effectiveness and the required passengers' experience is attained. In other words, the aim is to maximize the number of the checked-in passengers in the required quality keeping the costs minimal. However, the probability of the queue formation in the whole system cannot be fully neglected. The queues are important features with respect to the operational effectiveness. However, the queues existence may likely worsen the passengers' experiences. Therefore, the equilibrium is key when speaking of maintaining an optimal operation. This article discusses these two key factors and links them with the queuing theory.

\section{Passenger satisfaction}

As the main airports' objective (airlines and other commercial businesses) is to make profit, keeping the current customers (passengers) satisfied and attracting the new ones is particularly crucial regarding the sustainable development. This aim on building the customer's loyalty. If the company provides the quality services in the long-term with reasonable prices, it contributes to the brand position as the customer's loyalty to is based on the quality they perceive [1]. Its importance can be illustrated by the following. The airport's location and available destinations have an impact on the number of potential customers. Particularly in Europe where the density of airports is high, the competition is considerable. The passengers can choose from several airports that are in the vicinity. In that case, the brand loyalty and positive experience may be the factors based on which the passenger decides.

The satisfaction of the passengers influences many areas in air traffic. It may be revenue and cost, willingness of passengers to cooperate, or building and maintaining the brand name for example. The importance of commercial revenues is more and more important to today's airports [2]. A passenger that is satisfied is more likely to spend their money which increases the revenue of the airport's commercial zones [3]. In this we can see the link between the customer's positive experience and the profit.

The passenger's willingness to cooperate with the airport staff and obey the rules is given by the level of their satisfaction. In other words, the effectiveness of the check-in processes and the satisfaction correlate. For example, the willingness to cooperate and obey the rules results in reduced time spent at the security check [4]. The less satisfied passenger, the more time they needed to pass the security. Consequently, this causes the overall service rate to decreases and so does the efficiency of the process. As a result of the slower pace at the security checkpoints, the queues start to form lowering the passengers' comfort even more. Next example may be opening of other security checkpoints so as to increase the service capacity. However, such approach requires more security employees and technological equipment raising the costs.

In general, the satisfaction may be described as a difference between the passengers' expectations and their experi- ence in the real process [5]. This explanation explains why the airports attempt to affect the customers' satisfaction using the information tools such as providing notifications about the exceptionalities (temporary suspensions, reconstructions), introduction of new procedures and technologies, or operational problems (frequent delays, queueing times).

\section{Efficiency of the passenger terminal operations}

There are many aspects that may be used to assess and compare the efficiency. Speaking of the terminal process, the suitable criterion may be the ratio of total costs of the checkin process to total number of checked-in passengers. It allows monitoring the number of passengers on the chosen security track and calculating the required indicators during the day period. Moreover, the efficiency may be then compared with other airports. Concerning the security check, the short-term indicators of the efficiency may be assessed with respect to the long-term average values at each security track. The longterm indicators are suitable for comparing the performance with another airport not only in terms of number of passengers but also the cost per passenger.

The whole check-in process may be, however, negatively influenced by legislative or other requirements. Particularly, the security check of the passengers and their baggage is affected by the security standards that have to be met $[6,7]$. The security check, by its nature, has a significant effect on the quality that is perceived by the passengers [8]. Therefore, the new technologies are introduced and the new staff trained, however, this again increases the costs.

In order to maintain an efficient process, the number of employees and technologies has to correspond with the requirements at the specific point within process as much as possible. Whereas ensuring the higher capacity of service (the service rate is higher than the passenger arrival rate) raises the costs and lowers the efficiency, it provides greater comfort and is positively perceived by the travellers. In contrary, the low service rate leads to queue formation and lowers the level of passenger satisfaction. With regard to the complexity of the passenger terminal operations, the application of analytic tools for solving the capacity issues is not beneficial in the most of the cases. Unlike, the simulation tools allow us to model the complex processes providing a range of advantages thereby. Setting an optimal service intensities (technology, employees, ...) and maintaining the passenger satisfaction can be attained through correct planning and capacity management. Of course, the knowledge of the arrival intensity of passengers in time is necessary.

\section{Passenger arrival rate}

A precise prediction of number of arriving passengers in time is fundamental for strategic, tactic and operative planning of the whole processes. The strategic planning fulfils the operational requirements through the technology equipment 


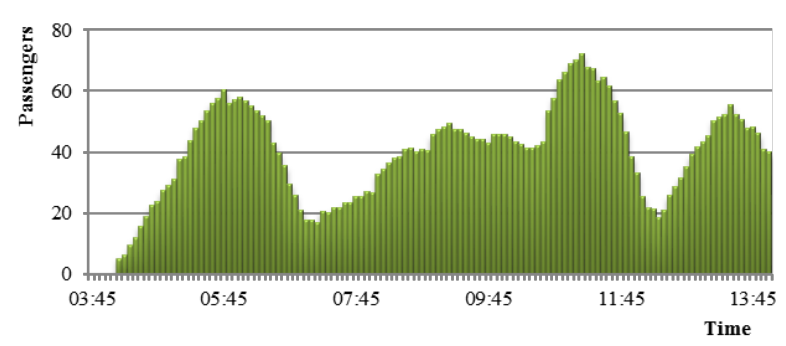

Figure 1. Model of passenger arrival intensity [9].

and staff. The maximal predicted arrivals which have to be managed are thus the most important data. With the time, the forecasts are being refined and, according to it, the operational requirements are stated more precisely. Of course, the passenger arrival predictions have to be sufficiently accurate. During the operative planning, the actual capacities are controlled regarding the passenger flow. Correspondingly, the precise data in the short-time are also needed concerning the queue management.

To some extent, the strategic and tactic predictions of passenger arrivals may be credibly estimated (see Fig. 1) from the flight schedule, distribution curves, aircraft capacities and expected utilization. In order to obtain the accurate shorttime predictions, the real-time monitoring of the operational situation, the data share among the involved parties and the parts of the whole process are necessary. Hence, the data sharing is a crucial factor for the successful data planning.

\section{Passenger queues}

An inevitable part of the passenger terminal process is the presence of the queues concerning the departing passengers. There are several reasons why they may form. The major cause is the imbalance between the arrival and service intensities. The arrival intensity is equal to the mean value of the number of customers entering per time. The arrival times are usually independent and have a common distribution (for example, customers arrive according to the Poisson stream) [10]. Since the service intensity is usually expressed as a mean value, maintaining the acceptable queue lengths leads to optimal utilization of the standpoints (check-in, security). Doing so, the available service intensity is efficiently utilized in case of the passenger arrival intensity fluctuations.

Other factors influencing the queue formation are various emergency situations (restriction due to operation outages or security reasons), technological restrictions (equipment failure, electricity outages), non-standard operation and traffic situations (congestions), or unexpected aircraft load factors (sport events).

In terms of the efficiency and the service quality improvement, it is beneficial to manage the passenger flows as well as the queues. It refers to the dynamic queue management using the analysis of and the modifications in check-in process based on the passenger categories (taking their needs and expectations in account) for instance [11, 12]. This may be illustrated by providing a special security checks tracks for the frequent passengers who are familiar with the security rules. Correspondingly, the greater information assistance is provided to those who are, in contrast, unfamiliar with the process and/or need more time to pass the security check (parents and their children, medical equipment).

\section{Conclusion}

As other companies participating in the passenger check-in process, the airports are also commercial subjects for which the revenue is important. Among other things, the high operational efficiency and the high level of the passenger satisfaction create conditions for the increase in profit. As it was described in the text, both factors are coupled considerably and have a great impact on the business success. The queue management is also effective approach contributing to the operation efficiency and reduction of the negative impacts on the passenger's experience. Therefore, the high efficiency and the passenger satisfaction are common interests of all organizations as well as the passengers.

\section{Acknowledgments}

This paper was supported by the Grant Agency of the Czech Technical University in Prague, grant No. SGS16/189/OHK2 /2T/16.

\section{References}

[1] N. Calisir, E. Basak, and F. Calisir. Key drivers of passenger loyalty: A case of frankfurt-istanbul flights. Journal of Air Transport Management, 53: 211-217, 2016. doi: 10.1016/j.jairtraman.2016.03. 002. URL https://doi.org/10.1016\%2Fj. jairtraman.2016.03.002.

[2] A. Graham. How important are commercial revenues to today's airports? Journal of Air Transport Management, 15(3):106-111, 2009. doi: 10.1016/j.jairtraman.2008. 11.004. URL https://doi.org/10.1016\%2Fj. jairtraman.2008.11.004.

[3] J.D. Power. Although Technology May Help Improve the Airport Experience, the Basics Have the Greatest Impact on Passenger Satisfaction, 2010. URL http: / / businesscenter.jdpower.com/ news/pressrelease. aspx? ID =2010015. [Online].

[4] A. Kirschenbaum. The cost of airport security: The passenger dilemma. Journal of Air Transport Management, 30:39-45, jul 2013. doi: 10.1016/j.jairtraman.2013. 05.002. URL https://doi.org/10.1016\%2Fj. jairtraman.2013.05.002. 
[5] M.K. CHING. Passengers' perception on airport service and quality satisfaction. In 10th International Academic Conference, pages 198-207, Vienna, 2014. International Institute of Social and Economic Sciences (IISES).

[6] V. Plos, P. Vittek, and V. Voštová. The possibility of using safety indicators to evaluate security at airports. Magazine of Aviation Development (SI), 2(2):9-12, 2015.

[7] I. Pastorčáková and E. Endrizalová. A crucial factor in aviation. Interdisciplinarity in Theory and Practice, 2(5): 67-71, 2015.

${ }^{[8]}$ K. Gkritza, D. Niemeier, and F. Mannering. Airport security screening and changing passenger satisfaction: An exploratory assessment. Journal of Air Transport Management, 12(5):213-219, 2006. doi: 10.1016/j.jairtraman. 2006.03.001. URL https://doi.org/10.1016\% 2Fj.jairtraman.2006.03.001.

[9] R. Vokáč, P. Vittek, and M. Lánský. The model for estimating passenger arrival rates. In Aeronautika XV, pages 109-112, Lublin, 2015. Lublin University of Technology.

[10] Leonard Kleinrock. Queueing systems. Wiley, New York, 1975. ISBN 0-471-49110-1.

[11] G. Bezerra and C.F. Gomes. The effects of service quality dimensions and passenger characteristics on passenger's overall satisfaction with an airport. Journal of Air Transport Management, 44-45:77-81, 2015. doi: 10.1016/ j.jairtraman.2015.03.001. URL https: //doi.org/ $10.1016 \% 2 \mathrm{Fj} \cdot j a i r t r a m a n .2015 .03 .001$.

${ }^{[12]}$ F. Ali, W.G. Kim, and K. Ryu. The effect of physical environment on passenger delight and satisfaction: Moderating effect of national identity. Tourism Management, 57:213-224, 2016. doi: 10.1016/j.tourman.2016. 06.004. URL https://doi.org/10.1016\%2Fj. tourman.2016.06.004. 